\title{
Correction to: An overview of M-government services in Saudi Arabia
}

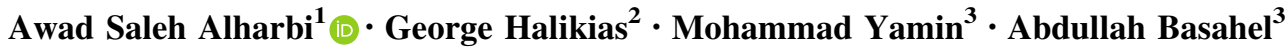

(C) Bharati Vidyapeeth's Institute of Computer Applications and Management 2020

\section{Correction to: Int. j. inf. tecnol.}

https://doi.org/10.1007/s41870-020-00433-9

In the original article, one of the co-author's (Abdullah Basahel) given name has been published incorrectly. The correct given name should be Abdullah.

The original article has been updated accordingly.

The original article can be found online at https:// doi.org/10.1007/s41870-020-00433-9.

Awad Saleh Alharbi

awad5858@yahoo.com

George Halikias

g.halikias@city.ac.uk

Mohammad Yamin

myamin@kau.edu.sa

Abdullah Basahel

abasahl@kau.edu.sa

1 Buraidah College of Technology, Buraidah, Saudi Arabia

2 Department of Electrical and Electronic Engineering, School of Mathematics, Computer Science and Engineering, London, United Kingdom

3 Faculty of Economics and Administration, King Abdulaziz University, Jeddah, Saudi Arabia 